\title{
A AUDIÊNCIA (SESSÃO) DE CONCILIAÇÃO E A PRÉ-MEDIAÇÃO NOS JUIZADOS ESPECIAIS CÍVEIS
}

\author{
THE CONCILIATION HEARINGS (SESSIONS) AND THE
} PREMEDIATION IN BRAZILIAN SMALL CLAIM COURTS

\author{
SALOMÃO AKHNATON ZOROASTRO SPENCER ELESBON \\ Juiz de direito. Especialista em direito civil, direito processual \\ civil e direito do consumidor. Mestrando do PPGPD/Enfam. \\ https://orcid.org/0000-0002-0496-3168
}

\begin{abstract}
RESUMO
O presente artigo examina a compatibilidade entre a mediação e o rito dos juizados especiais cíveis estaduais, no âmbito da Política de Tratamento Adequado de Conflitos. Foca sob o aspecto teleológico a missão dos juizados de expandir o acesso à justiça e disseminar os métodos autocompositivos, sob o signo da informalidade. Examina os aspectos distintivos da mediação e conciliação, e sugere a adaptação do procedimento para que, feito o diagnóstico do método mais adequado à solução do litígio, sejam adaptados os atos processuais à realização da pré-mediação, quando conveniente.
\end{abstract}

Palavras-chave: juizados especiais cíveis; resolução alternativa de conflitos; conciliação; mediação; acesso à justiça.

\section{ABSTRACT}

This paper examines the compatibility of mediation and the Brazilian Small Claims Courts procedure, within the scope of the National Conflict Resolution Policy. From the teleological point of view, it focuses on the mission of the Small Claims Courts, to expand access to justice and to disseminate self-composition methods, under the sign of informality. It examines the distinctive aspects of mediation and conciliation and suggests adapting the procedure so that, once the diagnosis of the most appropriate method for resolving the dispute is made, procedural acts are adapted to carry out pre-mediation, when appropriate. 
Keywords: civil small claim courts; alternative dispute resolution; conciliation; mediation; access to justice.

Recebido: 28-5-2021

Aprovado: 28-6-2021

\section{SUMÁRIO}

1 Os juizados especiais cíveis e os métodos consensuais de resolução de conflitos. 2 A conciliação, a mediação e o rito da Lei n. 9.099/1995. 3 Prémediação, autonomia da vontade e decisão informada. 4 Pré-mediação e o art. 21 da Lei n. 9.099/1995 - fluxo sugerido. 5 Conclusão. Referências.

\section{OS JUIZADOS ESPECIAIS CÍVEIS E OS MÉTODOS CONSENSUAIS DE RESOLUÇÃO DE CONFLITOS}

Os juizados especiais surgem em um contexto de preocupação com a maximização do acesso à justiça. O escopo primordial do microssistema é o de assegurar ao cidadão a tutela jurisdicional em circunstâncias tais em que lhe seria economicamente inviável demandar ou em que se veria desestimulado a fazê-lo sob o pálio dos procedimentos mais formais e morosos.

Ao isentar os custos iniciais da demanda e restringir a sucumbência a hipóteses específicas de presumível mau uso da jurisdição, bem como ao prescindir da intermediação por advogado, até o teto de 20 salários mínimos, o rito sumaríssimo da Lei n. 9.099/1995 proporciona a busca pela resolução dos conflitos, mesmo em situações de relativa pouca monta, arrostando o problema social da litigiosidade contida'.

O desígnio de favorecer o acesso à justiça, desimpedido de formalidades excessivas, e a proeminência conferida aos métodos

\footnotetext{
Expressão que teria sido cunhada por Kazuo Watanabe (2019 apud BACELLAR 2020, p. 209), ao analisar a realidade brasileira, na década de 1980, quando da elaboração do anteprojeto dos juizados especiais de pequenas causas.
} 
autocompositivos ${ }^{2}$ - que comunga com os postulados da dignidade humana e da liberdade de autodeterminação - dimanam da sede constitucional dos juizados, proclamada no art. 98, I, da Constituição Federal’3.

O pendor pelos métodos alternativos à jurisdição reverbera na Lei n. 9.099/1995, v.g., na remissão expressa à arbitragem e na ênfase dada à conciliação e transação, como modalidades compositivas à disposição das partes, admissíveis mesmo quando excedidos os limites estritos da competência ratione valorem dos JECs.

Conjuga-se tal preocupação com uma justiça de resultados, que possa se valer de todos os instrumentos disponíveis e em sintonia com os vetores estruturais do microssistema, destacadamente a informalidade e a simplicidade 4 . A justa resolução do conflito tem valor preponderante sobre a forma de que se revestiu o processo. Como admoesta Joel Dias Figueira Júnior:

[...] em que pese o rito previamente estabelecido para os juizados especiais em face da incidência do princípio da informalidade, nada obsta que o juiz busque soluções alternativas de ordem procedimental para obter uma prestação da tutela jurisdicional mais rápida e hábil a adequar a ação de direito material àquela de direito processual. [...] A Lei n. 9.099/1995 não está muito preocupada em preconizar a forma em si mesma; sua atenção fundamental dirige-se para a matéria de fundo, ou seja, a concretização, a efetivação do direito do jurisdicionado que acorreu ao Judiciário para fazer valer sua pretensão, com a maior simplicidade e rapidez possível. (FIGUEIRA JUNIOR; TOURINHO NETO, 2017, p. 97)

\footnotetext{
2 Sobre a distinção fundamental entre os métodos autocompositivos e adversariais, Bacellar (2020, p. 216) discorre: "Nos métodos consensuais, a partir das questões levantadas pelos interessados, as soluções advêm da vontade dos próprios interessados - solução autocompositiva, independentemente de qualquer produção probatória ou de decisão de terceiro, por isso, nesses métodos, priorizam-se as formas autocompositivas (negociação, conciliação, mediação). O método adversarial na forma heterocompositiva sempre foi a regra no sistema processual brasileiro e por meio dele o juiz, após ouvir as partes e colher a prova, impõe a decisão e adjudica o direito em favor de uma das partes (ganha/perde). A mesma situação se verifica com a arbitragem que, embora na origem, para se instaurar, dependa de um consenso, se desenvolve na forma heterocompositiva".

3 "Art. 98. A União, no Distrito Federal e nos Territórios, e os Estados criarão: I - juizados especiais, providos por juízes togados, ou togados e leigos, competentes para a conciliação, o julgamento e a execução de causas cíveis de menor complexidade e infrações penais de menor potencial ofensivo, mediante os procedimentos oral e sumaríssimo, permitidos, nas hipóteses previstas em lei, a transação e o julgamento de recursos por turmas de juízes de primeiro grau." (BRASIL, 1988)

4 Nas palavras de Alexandre Freitas Câmara (2008, p. 17): "Essa informalidade é essencial para que os juizados atinjam um de seus principais escopos: aproximar o jurisdicionado dos órgãos estatais incumbidos de prestar jurisdição. O formalismo inibe, assusta, afasta o jurisdicionado, sendo por isso mesmo contrário aos princípios que inspiram o funcionamento dos juizados especiais cíveis".
} 
○ impacto da abertura dessa porta é inegável. O relatório Justiça em Números 2020 (BRASIL, 2020b, p. 52) informa que o número de casos novos em primeiro grau, nos juizados especiais estaduais, foi de 5.193.140, no ano-base 2019, ao passo que os demais segmentos da justiça estadual receberam 12.155.205 casos novos no mesmo segmento ${ }^{5}$.

A duração média do processo nos juizados especiais estaduais é de 1 ano e 6 meses até a baixa, na fase de conhecimento e na execução de títulos extrajudiciais. A execução de título judicial perdura um pouco mais, 1 ano e 7 meses. Em termos de duração razoável do processo, o microssistema se sobressai nitidamente, em cotejo com os outros ramos da Justiça estadual, nos quais o processo de conhecimento, até a baixa, tramita em média por 3 anos e 7 meses (sendo 7 anos e 7 meses na execução extrajudicial; e na judicial, por 4 anos e 2 meses). (BRASIL, 2020b, p. 51)

Em suma, os juizados especiais estaduais absorveram aproximadamente 30\% dos casos novos em 2019 (29,934\%). A despeito disso, mantiveram um tempo médio de resolução significativamente menor, aquém da metade.

Resulta que o estoque processual, em termos de casos pendentes, foi de 5.498.856 nos juizados especiais, e de 52.893.618, nos juízos comuns, representando apenas $9,41 \%$ do estoque total nas unidades judiciais em primeiro grau. Ao cabo, a taxa de congestionamento foi de $48,7 \%$ nos juizados e de $77 \%$ nos demais ramos da Justiça estadual (BRASIL, 2020b, p. 52-53). Tudo isso, em que pese a estrutura dedicada a eles fosse inferior ao das unidades judiciárias dotadas de competências ordinárias ${ }^{6}$.

\footnotetext{
5 "O Poder Judiciário finalizou o ano de 2019 com 77,1 milhões de processos em tramitação, que aguardavam alguma solução definitiva. Desses, 14,2 milhões, ou seja, 18,5\%, estavam suspensos, sobrestados ou em arquivo provisório, e esperavam alguma situação jurídica futura. Dessa forma, desconsiderados tais processos, tem-se que, em andamento, ao final de 2019, existiam 62,9 milhões ações judiciais." (BRASIL, 2020b, p. 93)

6 Somente 9,7\% das unidades judiciárias consistem em juizados especiais, levando em consideração todas as competências e os segmentos do Poder Judiciário. O relatório computa 3.204 magistrados e 20.300 servidores em juizados especiais estaduais, e 9.367 magistrados e 112.149 servidores em unidades judiciárias comuns, levando em conta o primeiro grau. Vale dizer que, dada a metodologia empregada no relatório, haverá sobreposição desses conjuntos, nas unidades em que há competências híbridas. "Dos 15.552 juízes de direito, 13.817 atuam no juízo comum, sendo 9.894 (71,6\%) de forma exclusiva, 2.808 (20,3\%) com acúmulo de função em juizados especiais e 1.115 (8,1\%) em conjunto com turmas recursais. Magistrados exclusivos em juizados especiais são apenas 1.176, ou seja, correspondem a 7,6\% dos juízes e a $28,1 \%$ daqueles que atuam em juizados cumulativamente ou não (4.182), enquanto 198 (4,7\%) acumulam com as turmas recursais. Dos que exercem jurisdição em turmas recursais (1.674), 2,3\% o fazem de forma exclusiva”. (BRASIL, 2020b, p. 31, 53, 89)
} 
Os índices de conciliação também se destacam nos juizados estaduais, alcançando a cifra de $23 \%$, em cotejo com os $14,3 \%$ dos demais segmentos da Justiça estadual em primeiro grau. (BRASIL, 2O2Ob, p. 173)

A vocação precípua dos juizados especiais, desde o seu nascedouro, é o fomento à autocomposição ${ }^{7}$. E sobre a coexistência harmônica entre as modalidades estatais adjudicadas e autocompositivas ${ }^{8}$, Nicácio (2012, p. 39) pondera:

[...] à justiça formal não cabe julgar todas as questões que the são endereçadas, ao passo que os meios consensuais não podem e não devem resolver todas as questões que Ihe são levadas a conhecer. É necessário senso de adequação e de oportunidade, como também ações pedagógicas visando sensibilizar o público de cidadãos sobre a existência de diferentes mecanismos de regulação, bem como suas particularidades e limites.

Uma vez que os juizados especiais nascem com o propósito de consolidar e incrementar o repertório de métodos resolutivos dos conflitos, não deve o seu rito ser enfocado como estanque ou imobilizado no tempo, antes, permeável a todas as evoluções subsequentes a sua implantação. A Lei n. 9.099/1995 pode e deve ser relida em harmonia com o novo contexto vigente, da política nacional de resolução dos conflitos.

\section{A CONCILIAÇÃO, A MEDIAÇÃO E O RITO DA LEI N. 9.099/1995}

O art. 1ํ da Resolução CNJ n. 125/2010 assegura a todos, textualmente, o direito à solução dos conflitos por meios adequados à sua natureza e peculiaridade. O Código de Processo Civil, de igual modo, enaltece a autocomposição e exorta os atores processuais a estimulá-la

\footnotetext{
7 "Diante da magnitude do tema e, em particular, da sua importância em sede de juizados especiais, vale repetir que a principal atribuição [...] conferida constitucionalmente (art. 98, I, CF) à Justiça Especializada é a autocomposição das partes, de maneira a permitir a resolução dos conflitos sem a imposição da decisão pelo Estado-Juiz (ius imperi), pacificando os litigantes de acordo com seus próprios interesses e possibilidades, por eles próprios encontradas em suas tratativas, permitindo, assim, a maior satisfação dos envolvidos." (FIGUEIRA JÚNIOR; TOURINHO NETO, 2017, p. 98)

8 Recordando, como o faz Bacellar (2020, p. 216), que os métodos alternativos e extrajudiciais de solução de conflitos também podem ser consensuais ou adversariais, dentre os primeiros, contando-se a negociação, mediação e conciliação e, dentre os últimos, a arbitragem.
} 
e praticá-la em todas as etapas, ainda que pré-processuais (art. 3으, §§ $2^{\circ}$ e $\left.3^{\circ}\right)^{9}$. São estatutos legais e regulamentares que se complementam e entrelaçam ao microssistema dos juizados especiais, no que respeita aos meios consensuais de resolução de conflitos.

Bacellar (2020, p. 205) descreve a resolução alternativa de disputas (ADR) como:

[...] a que decorre dos processos de negociação, de mediação e de arbitragem fora do âmbito do sistema oficial de resolução de disputas que são os tribunais" e salienta que a sua qualidade de "alternativas ao sistema oficial" advém exatamente da circunstância de que surgiram para serem aplicadas fora dos juízos, considerados em seu sentido amplo.

Nicácio (2012, p. 25) define os meios consensuais como "uma intervenção não autoritária de terceiro, visando ao aprimoramento da comunicação entre indivíduos e grupos, para a prevenção ou resolução de conflitos, bem como para a criação e reparação de laços sociais".

A inserção da mediação nesse contexto não apresenta antinomia com as regras e os princípios dos juizados especiais cíveis. Conquanto o texto da Lei n. 9.099/1995 remeta singelamente à audiência de conciliação, não há razão para supor que a abordagem do conflito deva cingir-se a essa modalidade específica. Até porque a oferta dos meios adequados de resolução de controvérsias, à luz da Resolução CNJ n. 125, pode ser compreendida como um genuíno direito do cidadão ${ }^{10}$.

Além do aspecto valorativo, a competência dos juizados especiais cíveis apresenta limitações sobretudo de índole pessoal. Mas as restrições

\footnotetext{
9 "Art. 3으...] § 2으 $\bigcirc$ Estado promoverá, sempre que possível, a solução consensual dos conflitos. § 3ำ A conciliação, a mediação e outros métodos de solução consensual de conflitos deverão ser estimulados por juízes, advogados, defensores públicos e membros do Ministério Público, inclusive no curso do processo judicial". (Brasil, 2015a)

10 Propugnando essa ótica, Watanabe (2020, p. 134-135): "A Resolução n. 125, do Conselho Nacional de Justiça, editada em novembro de 2010, acolheu esse conceito atualizado de acesso à justiça, com toda a sua significação e abrangência, e instituiu uma importante política judiciária nacional de tratamento adequado dos conflitos de interesses. Deixou assentado, em sua exposição de motivos, que o direito de acesso à justiça é acesso à ordem jurídica justa, e em seus dispositivos deixou expressamente declarado que os jurisdicionados têm direito à solução dos conflitos pelos métodos mais adequados à sua solução, em especial os métodos consensuais (mediação e conciliação) e que os órgãos do Judiciário brasileiro têm a obrigação de oferecer esses serviços, prestados com qualidade e por pessoas devidamente capacitadas e treinadas".
} 
materiais são relativamente poucas. Contidas no limiar de 40 salários mínimos e observadas as causas imunes a esse balizamento máximo, uma enormidade de assuntos aportam cotidianamente por essa via.

É bem verdade que, do ponto de vista do indivíduo, pessoa natural, as questões de fundo consumeristas, envolvendo grandes fornecedores, são as mais frequentes ${ }^{11}$. A extensão da legitimatio ad processum para outros entes coletivos, mormente microempresas e empresas de pequeno porte ${ }^{12}$, também prodigalizou ações de cobrança e disputas de indole empresarial. Contudo, traçados os subconjuntos de tais assuntos mais demandados, a variedade dos demais impressiona e revela que a menor complexidade (hoje focada sobretudo pelo viés probatório) nem sempre condiz com as expectativas iniciais do legislador.

Em um cenário de tamanha amplitude temática, fato é que as causas e condições preexistentes aos conflitos e os meios adequados para sua resolução também variam amplamente e cabe aos operadores do direito estarem sensíveis a isso.

O art. 1, parágrafo único, da Resolução CNJ n. 125/2010, não apenas preconiza que os órgãos judiciários devem oferecer outros mecanismos de solução de controvérsias, antes da sentença - notadamente os meios consensuais -, mas vai além, e inscreve no conteúdo mínimo dessa prestação o atendimento e a orientação ao cidadão.

Mendes e Hartmann (2018, p. 111, 125) recordam que a antecipação da audiência de autocomposição no novo CPC, antecedendo o oferecimento da contestação, encontra paralelo com o rito dos juizados especiais cíveis.

\footnotetext{
1 O direito do consumidor figura entre os assuntos de maior destaque nos juizados especiais estaduais. A primeira colocação na justiça estadual como um todo, com 4,44\% dos casos novos, apresenta o assunto "Direito do Consumidor - Responsabilidade do Fornecedor/Indenização por Dano Moral", associado a 2.295.880 processos. "Direito Civil - Obrigações/Espécies de Contratos" surge na segunda colocação, em 2.227.212 processos (4,31\%). O quarto assunto mais demandado é "Direito Civil - Responsabilidade Civil/Indenização por Dano Moral”, em 1.356.290 (2,63\%). Não é de se espantar que três, dentre os cinco assuntos mais frequentes, são corriqueiros nos juizados especiais estaduais. Faz-se o registro de que mais de um assunto pode constar de um único processo e disso decorre a disparidade entre os somatórios dos assuntos e o total de casos ingressados em cada segmento no ano de 2019. (BRASIL, 2020b, p. 237-238)

12 Estas, por menção expressa na Lei n. 9.099/1995 (além de outros entes enumerados no art. 8으, § 1ำ). Mas os condomínios, embora não qualificados como pessoas jurídicas, também passaram a figurar costumeiramente nos juizados especiais, por conformação da doutrina e prática jurisprudencial. Consulte-se, quanto a isso, o Enunciado n. 9, do Fórum Nacional de Juizados Especiais - Fonaje.
} 
O objetivo seria evitar que a formulação da defesa acentuasse a polarização entre as partes, favorecendo, portanto, a solução consensual dos conflitos. $\mathrm{E}$, concluindo o círculo, remetem à influência do CPC (e do conjunto da legislação sobre métodos autocompositivos) sobre os juizados especiais, sustentando a aplicação subsidiária de tal regramento ao microssistema, notadamente quanto à oferta da conciliação e da mediação, à habilitação e atuação dos facilitadores e à possibilidade de realização da primeira audiência do rito sumaríssimo nos Cejuscs. Traça-se uma via circular, em que o microssistema e O CPC se influenciam-se mutuamente ${ }^{13}$. Sempre que suas regras se harmonizem por uma principiologia comum, devem os juizados se abeberar das inovações do processo civil ordinário, que com ele dialoguem.

Nada obsta, portanto, que mesmo no rito dos juizados especiais seja a mediação empregada, quando se revele adequada. Com efeito, "um dos princípios que orientam o processo de múltiplas portas é o princípio da adaptabilidade que informa que o procedimento há de se afeiçoar às peculiaridades de cada litígio". (BACELLAR, 2020, p. 212)

Nada obsta, portanto, que mesmo no rito dos juizados especiais seja a mediação empregada, quando se revele adequada. Com efeito, "um dos princípios que orientam o processo de múltiplas portas é o princípio da adaptabilidade que informa que o procedimento há de se afeiçoar às peculiaridades de cada litígio". (BACELLAR, 2020, p. 212)

Bacellar (2020, p. 217-218) defende a conciliação como instrumento autocompositivo primordial em juízo, por sua tradição e economia ${ }^{14}$, mas isso não dispensa uma análise mais acurada dos casos postos, para que outros direcionamentos sejam adotados, conforme a natureza e as características do conflito.

Ao tentar extremar as modalidades de conciliação e mediação, o Código de Processo Civil estatui, no art. 165, § 2․, que o conciliador exercerá suas funções "preferencialmente nos casos em que não houver

\footnotetext{
13 Conforme Bacellar (2020, p. 215): "Percebe-se que o Código de Processo Civil apresenta a preocupação de viabilizar não só o acesso, mas também a prevenção e fundamentalmente a saída da justiça de forma adequada, já que é grande o estoque de casos que precisam encontrar uma solução adequada, de preferência célere e eficaz".

14 Nas palavras do autor: "A nossa posição é no sentido de que em todas as unidades judiciárias, principalmente nos Cejuscs, trabalhe-se preferencialmente com a conciliação. [...] Ainda assim, apenas quando a conciliação eventualmente não for adequada ou resultar negativa é que teremos de promover a indicação de outro meio, o que poderá ser feito pelo próprio conciliador - capacitado e preparado para orientar as partes e redirecionar a causa".
} 
vínculo anterior entre as partes e poderá sugerir soluções para o litígio". Conforme Faleck (2018, p. 126), "o conciliador teria papel mais interventivo, e, portanto, a prerrogativa de: (i) avaliar e manifestar sua opinião sobre o mérito das alegações das partes; e (ii) sugerir a opção de acordo". O mediador, de seu turno, atuará preferencialmente nos casos em que existir o liame anterior entre as partes. E, na dicção do § 3으o mesmo dispositivo, "auxiliará os interessados a compreender as questões e os interesses em conflito, de modo que eles possam, pelo restabelecimento da comunicação, identificar, por si próprios, soluções consensuais que gerem benefícios mútuos"15.

A despeito do marco legal vigente, Faleck (2018, p. 126) chama a atenção para o fato de que outros critérios podem ser adotados para distinguir, no caso concreto, a melhor aplicação de tais métodos, "como, por exemplo, a previsibilidade do resultado judicial, o grau de repetitividade da demanda, o grau de necessidade de confiança no neutro, a vontade das partes, entre outros".

Bacellar (2016, p. 119-120) sumariza que na natureza do conflito e da relação reside uma das diferenças primordiais entre conciliação e mediação. "A mediação é mais adequada para relações multiplexas (de vários vínculos) e a conciliação para relações mais simples, de um único vínculo [...]". Também se distinguem pela finalidade e pelo foco, a conciliação, centrada na obtenção de um acordo e na extinção do processo, e a mediação, em restabelecer a comunicação e "auxiliar os interessados a desvendar os verdadeiros interesses, desejos, necessidades (lide sociológica) que se escondem por trás das posições (lide processual)". Por fim, diferem na atuação do terceiro facilitador, visto que o conciliador está autorizado a opinar sobre o mérito do acordo, sugerir soluções, participando de modo mais ativo, porém mais superficial. Foca nos pontos contraditórios objeto da lide. O mediador, de seu lado, lança o olhar sobre o relacionamento e para tanto:

\footnotetext{
15 "O mediador nem resolve, nem aconselha, nem sugere porque ele não sabe nada dessas pessoas, do que acontece entre elas, nem de suas realidades, nem da questão a ser trabalhada. [...] Daí que só eles sabem dos seus conflitos e da melhor maneira de resolvê-los. Isto é a base para possibilitar uma verdadeira autocomposição a partir do respeito e da cooperação. Quando conseguida, a autocomposição é a maior garantia de emancipação por ser o procedimento que permite às pessoas exercerem os seus direitos plenamente por terem atingido o grau de maturidade psicossocial (ser adulto) para estar em condições de tomar as suas próprias decisões". (VEZZULLA, 2013, p. 78)
} 
[...] facilita e restabelece a comunicação; auxilia os interessados a compreender as questões; procura identificar de modo amplo os interesses e aprofundarse nas relações, sem limitação de matéria ou escassez de tempo; faz perguntas criativas com a finalidade de que os próprios interessados identifiquem os interesses mútuos e encontrem as soluções por ele desejadas. (BACELLAR, 2016, p. 120)

Os exemplos retirados da prática forense são pródigos: disputas sobre regras de convívio e vizinhança; cobranças de cotas condominiais; ações possessórias que por pano de fundo quizilas familiares; danos morais oriundos de desavenças entre ex-conviventes e seus atuais consortes. Muitos são os casos em que o recorte da lide formalizada em juízo, albergada pela competência dos juizados, constitui apenas uma parcela mínima do litígio sociológico subjacente e apenas um aspecto acanhado das multifárias relações que entrelaçam as pessoas em conflito. A complexidade e a continuidade desses relacionamentos é um indicador relevante de que a abordagem conciliatória clássica, pontual, possa ceder espaço à intervenção do mediador, para restabelecimento duradouro do diálogo entre os litigantes.

Faleck (2018, p. 114-117) menciona a existência de barreiras cognitivas, padrões com que as pessoas reagem durante as negociações e que podem obstaculizar a obtenção de resultados que atendam aos seus próprios interesses. Cita dentre eles a aversão ao risco e à perda, a desvalorização reativa, o excesso de confiança, o fixed-pie bias e o conflito de agência. Apoiado em Goldberg, defende a mediação como mecanismo processual idôneo a suplantar tais óbices e predisposições negativas, sobretudo porque o mediador poderá: encorajar a troca de informação; ajudar as partes a entender que suas visões foram consideradas; promover um nível produtivo de expressão emocional; lidar com as diferenças de percepções e interesses entre negociadores e constituintes; encorajar flexibilidade; mudar o foco do passado para o futuro; estimular as partes a sugerir acordos criativos etc.

Vezzulla (2013, p. 77) realça que o escopo último "do procedimento da mediação não é atender exclusivamente a materialidade do conflito - um contrato ou uma partilha de bens - o seu objetivo é atender as pessoas envolvidas em conflitos". Do mediador se espera que seja um novo profissional, com uma nova perspectiva. Não Ihe cabe explorar o poder do conhecimento, para impor respostas, mas trabalhar para que "os participantes se apoderem de seus problemas e 
trabalhem na sua solução". Seu papel seria o de auxiliar "na comunicação, no relacionamento, no aprofundamento e compreensão dos reais problemas e na obtenção de informação suficiente" para que cada qual esteja apto a decidir satisfatoriamente e com segurança. (VEZZULLA, 2013, p. 79)

Desaconselhável, todavia, que haja a imposição por essa ou aquela modalidade, visto que a voluntariedade está no cerne de tais meios ${ }^{16}$.

\section{PRÉ-MEDIAÇÃO, AUTONOMIA DA VONTADE E DECISÃO INFORMADA}

O princípio da autonomia da vontade das partes está insculpido no art. $2^{\circ}, \bigvee$, da Lei de Mediação, cujo § $2^{\circ}$ dispõe categoricamente que ninguém será obrigado a permanecer em procedimento de mediação. E as sessões subsequentes, com presença das partes, somente poderão ser agendadas com o consentimento destas, tal qual enuncia o art. 18, do mesmo texto legal.

Não sem motivo, um dos princípios que norteiam a autocomposição é o da decisão informada, que incumbe ao facilitador o dever de manter plenamente esclarecidas as partes quanto aos direitos e ao contexto fático em que estão inseridas, de modo a que se possa alcançar isonomia efetiva e acordos mutuamente benéficos, sem abusos de lado a lado. (PEIXOTO, 2018, p. 102)

Em um conceito mais abrangente de acesso à ordem jurídica justa, a informação reveste-se de capital importância. Não se trata de mero acesso ao Poder Judiciário ${ }^{17}$, abarcando a necessidade de orientação,

\footnotetext{
16 Vezzulla (2013, p. 85) adverte sobre o efeito negativo de uma mediação indicada pelo juiz, pois esta pode ser considerada pelos advogados como uma imposição, que deve ser acatada, para não ensejar uma predisposição negativa do julgador. Com isso, deixando de haver uma adesão genuinamente voluntária, torna-se apenas um trâmite formal a cumprir, ao qual se submetem para contentar o juiz.

17 "[...] o ajuizamento de uma demanda judicial, por si só, não soluciona os conflitos. A falta de amparo prévio e posterior ao ajuizamento da ação acarreta prejuízos às partes não assistidas (na maioria dos casos hipossuficientes, com nítidas condições de desigualdades), desde o retardamento na solução final do litígio até o perecimento de direitos. [...] As carências estruturais e de qualificação dos servidores bem como o desprestígio institucional levado a cabo pelos dirigentes dos tribunais podem transformar os juizados especiais em 'falsas percepções' de acesso aos direitos e à justiça, ou seja, apenas como portas abertas para a entrada de demandas, e com dificuldades de abrir as portas de saída que propiciem a efetiva concretização da justiça." (BOCHENEK, 2013, p. 513-514)
} 
informação e auxílio jurídico, inclusive para conhecimento e emprego dos meios alternativos à jurisdição estatal. A questão que se coloca é a dignidade da pessoa ${ }^{18}$ e o pleno exercício da cidadania, o que é ínsito ao pensamento de Watanabe (2019, p. 121):

[...] impõe-se uma rápida consideração sobre o conceito atualizado de acesso à justiça, que não significa mero acesso aos órgãos judiciários. No conceito atualizado, o acesso à justiça constitui, em nossa avaliação, muito mais acesso à ordem jurídica justa, no sentido de que assiste a todos os jurisdicionados o direito de ser atendido pelo Sistema de Justiça, na acepção ampla que abranja não somente os órgãos do Poder Judiciário preordenados à solução adjudicada dos conflitos de interesses, como também a todos os órgãos, públicos e privados, dedicados à solução adequada dos conflitos de interesses, seja pelo critério da adjudicação da solução por um terceiro, seja pelos mecanismos consensuais, em especial a negociação, a conciliação e a mediação, e significa, ainda, direito de acesso à informação e orientação, não unicamente em relação a um conflito de interesses como também a problemas jurídicos que estejam impedindo o pleno exercício da cidadania, mesmo que não configurem um conflito de interesses com um terceiro. Essa concepção mais abrangente de acesso à justiça está em perfeita sintonia com os direitos fundamentais individuais e coletivos assegurados pela Carta Política, cujo fundamento maior é a dignidade humana, com plena possibilidade de exercício da cidadania (art. 1ํ, incisos II e III).

Nesse momento, avulta a conveniência da pré-mediação. "Como a mediação é voluntária, os participantes deverão conhecer o seu funcionamento, o trabalho a ser realizado pelo mediador e o que se espera deles antes de decidir se desejam ou não usar esse procedimento". (VEZZULLA, 2013, p. 80)

\footnotetext{
18 Apoiando-se em José de Albuquerque Rocha (2007), Vezzulla (2013, p. 74) preconiza: "A dignidade humana é, pois, a base sobre a qual se ergue o Estado e toda a ordem jurídica. Assim, a relação entre dignidade humana e acesso à justiça é uma relação entre meio e fim, já que é o acesso à justiça que vai assegurar a realização dos direitos fundamentais que são exatamente os meios através de cujo exercício a pessoa humana materializa sua dignidade, ou seja, desenvolve e aperfeiçoa sua personalidade".
} 
Com isso, ainda que não haja adesão ao procedimento, ou não se consiga o dimensionamento material do conflito ou o alcance do acordo, as partes, sem dúvida, estarão melhor informadas, e poderão se preparar para o eventual prosseguimento na disputa judicial, inclusive com o gerenciamento mediante a negociação processual (art. 190 do CPC/2015). (CURY, 2018, p. 512)

Galvão Filho (2018) propugna que a primeira audiência a que se refere o art. 334 do CPC/2015 não deve ser reputada uma audiência ou sessão ${ }^{19}$ de mediação propriamente dita, senão uma pré-mediação:

[...] nesta primeira audiência judicial, na verdade, as partes serão apresentadas ao que seria a Mediação, ou seja, uma verdadeira audiência de apresentação à mediação, o que na prática da mediação é denominada audiência ou sessão de pré-mediação.

Este esclarecimento é muito importante, pois as partes de um processo judicial não serão e não deverão ser lançadas imediatamente dentro de uma Mediação, mas apresentadas ao instituto e, após estarem devidamente esclarecidas, apresentar sua opção livre, espontânea e individual em optar pela adoção ou não por este método de prevenção ou solução de conflitos, na busca de um caminho para o enfrentamento da questão que possuem entre si. (GALVÃO FILHO, 2018, p. 530-531)

O mesmo posicionamento é defendido por Valeria Lagrasta, ao discorrer sobre o art. 334, § 12, do CPC/2015. Focando na prémediação, como abordagem preambular, ressalta que o escopo é a mudança cultural, possibilitando que as partes conheçam os métodos

\footnotetext{
${ }^{19}$ A referência à audiência e sessão, simultaneamente, advém da circunstância de que, não obstante na prática forense, os atos sejam indiscriminadamente designados por "audiências", tanto a Lei n. 9.099/1995, ao referir-se à conciliação, quanto a Lei n. 13.140, ao cuidar da mediação, referem-se a "sessões" de conciliação e mediação. O Código de Processo Civil, no art. 334, utiliza ambos os termos, sem distinção. Para Galvão Filho ("A audiência [...] é conceituada como um ato do procedimento de mediação, em que os mediandos [...] se reúnem na presença de um ou mais terceiros [...] para deliberar de forma pública sobre questões inerentes à mediação [...]. Por sua vez, a sessão [...] é conceituada como um ato do procedimento de mediação, em que os mediandos se reúnem na presença de um ou mais terceiros [...] para deliberar de forma reservada ou privada sobre questões relacionadas à mediação, que devem ser tratadas em sigilo (total ou parcial), seja pela natureza da matéria ou pela escolha das partes [...]. Portanto, a diferença ora proposta se refere ao grau de publicidade e ao grau de sigilo de cada ato do processo de mediação [...]”. (Galvão Filho, 2018, p. 525-526)
} 
consensuais de solução de conflitos e, se for o caso, optem por eles de maneira consciente ${ }^{20}$. O fim último é a transformação da cultura adversarial, propensa aos meios adjudicatórios, para a cultura da pacificação, inclinada aos instrumentos cooperativos. (LUCHIARI, 2020, p. 503-516)

De tal arte, o exíguo tempo mínimo de 20 minutos, claramente insuficiente para uma mediação de qualidade, pode ser utilizado para apresentar aos envolvidos o método para sua desenvoltura ulterior, em uma ou múltiplas sessões agendadas conforme a conveniência e utilidade.

Galvão Filho (2018, p. 535-536) acentua, porém, que não se trata de um mero ato simbólico, mas de uma relevante etapa de esclarecimento, em que o mediador: exporá às partes o que é mediação; explicará sua forma e funcionamento ideal; discorrerá sobre seus princípios; indicará as normas legais aplicáveis; esclarecerá o papel do mediador e a participação dos contendores, seus direitos, deveres etc; e apresentará o termo de adesão e, caso possível, lavrará um termo ou ata, registrando os comparecimentos e as informações prestadas.

A relevância desse novo momento procedimental está em disseminar a informação, que é um dos pressupostos essenciais do sucesso dos meios autocompositivos. Uma vez mais, assoma o magistério de Bacellar (2020, p. 210-211):

A postura cooperativa, no ambiente do Poder Judiciário e a percepção de que deve prevalecer um juízo de adequação, pode auxiliar o sistema brasileiro na melhora quantitativa dos índices de acordo. Nota-se que no Brasil é quase insignificante (se compararmos com outros países) o percentual de soluções pacíficas extrajudiciais, pré-processuais, nos escritórios de advocacia, ou encontradas por meio de câmaras privadas de solução de conflitos. [...]

Nos países que adotam a common law, a judicialização é sempre desestimulada e ocorre um incentivo permanente para as soluções extrajudiciais,

\footnotetext{
${ }^{20}$ Entretanto, a autora sublinha que, na prática, a pré-mediação, como a mediação propriamente dita, tem sido vítima da pressa e do desconhecimento e que, quando ocorre, a pré-mediação acaba sendo condensada e absorvida pela fase de abertura ou acolhida, seguindo-se incontinenti o procedimento de mediação. Perde-se a chance, dentre outras, da participação de outro conciliador/mediador, como seria recomendável.
} 
administrativas e preventivas, como a Discovery pelos advogados (investigação, pesquisa dos fatos e busca de provas antes do ajuizamento da ação) que só demandam se isso for imprescindível e adequado. [...]

Parte desses comandos atípicos, diversos da solução adversarial imposta pelo Poder Judiciário, ainda não são conhecidos. Já se afirmou que ninguém valoriza o que não conhece, talvez, por isso, das várias possibilidades atípicas que o sistema jurisdicional brasileiro oferece ao cidadão, a solução litigiosa, adjudicada (imposta) tem sido a preferida.

Como esclarece Cury, o caráter voluntário dos métodos autocompositivos não infirma a obrigatoriedade de que os contendores mantenham esse primeiro contato, devendo a sessão ser instalada, independentemente da perspectiva de continuação ou de resultado. Trata-se de uma oportunidade excelente para a pré-mediação, "permitindo que as pessoas envolvidas conheçam os princípios e os procedimentos e avaliem se se trata do método de eleição para a solução de seus conflitos". (CURY, 2018, p. 511-512)

Assim, por exemplo, quanto à audiência do art. 334, do CPC, sob a ótica de sua compulsoriedade, tem-se defendido que se trata de obrigatoriedade de designação e comparecimento ao ato, presentes as condições legais, não de sujeição das partes à conciliação ou mediação enquanto procedimentos.

\section{PRÉ-MEDIAÇÃO E O ART. 21 DA LEI N. 9.099/1995 - FLUXO SUGERIDO}

A plasticidade do rito da Lei n. 9.099/1995, que é uma consequência necessária da simplicidade e informalidade, rende ensejo a que o ato costumeiramente destinado à conciliação seja aproveitado como um momento de pré-mediação, apresentando às partes e seus advogados ${ }^{21}$ a disponibilidade,

\footnotetext{
${ }^{21}$ Vezzulla (2013, p. 86; 2014, p. 123), a partir de sua experiência, reconhece um papel importante para os advogados na mediação, como efetivos colaboradores, o que pressupõe a formação para o diálogo e o respeito à ética cooperativa.
} 
as características e vantagens desse método. Sempre respeitando-se, é certo, a voluntariedade.

Cabe assinalar que as sanções ao não comparecimento são aquelas preconizadas na Lei n. 9.099/1995, que impõe ao demandante ausente a extinção do processo, sem resolução do mérito, com pagamento das despesas do processo (art. 51, I e § 2º ) ao réu, os efeitos da revelia (art. 20)22. Isso não inibe que sejam apresentadas às partes presentes as opções autocompositivas ${ }^{23}$.

Nesse sentido é que, no âmbito do juizado especial cível, é possível falar-se na apropriação das regras e dos princípios do processo civil comum e da política nacional de tratamento adequado de conflito de interesses: incorporando à etapa compulsória da conciliação, do art. 21 da Lei n. 9.099/1995, a pré-mediação, para apresentar às partes a metodologia e facultar-Ihes o prosseguimento na mediação, em sessões oportunamente concertadas, se assim desejarem.

Por óbvio que se trata de uma abordagem a ser operada quando identificada a conveniência da mediação, como meio autocompositivo adequado. Isto, por sua vez, reclama a triagem eficaz dos processos.

Recomendável que os servidores do setor de atermação inicial ${ }^{24}$ estejam capacitados a discernir o melhor encaminhamento, porventura sugerindo a mediação a priori, em caráter pré-processual, nos Cejuscs ${ }^{25}$,

$\overline{22} \mathrm{O}$ art. 334, § 8으. do CPC, considera ato atentatório à dignidade da justiça e prescreve multa aos que injustificadamente não comparecerem, ressalvadas as situações do $\S 4$, do mesmo dispositivo.

${ }^{23}$ Afinal, o julgamento com base na revelia pode não assegurar o recebimento do bem da vida desejado. E, embora mais raramente, a extinção sem julgamento do mérito pode desinteressar até mesmo ao réu, que almeja resolver a pendência e desvencilhar-se da situação de conflito. Por fim, sua posição de incerteza é agravada pela permissão de que a demanda seja ajuizada novamente, com custos em termos de tempo e dinheiro.

24 Das partes sem advogado, segundo o diagnóstico dos juizados estaduais, realizado pelo Conselho Nacional de Justiça, o setor de atermação absorve em torno de dois terços dos atendimentos iniciais (61,7\% nos juizados adjuntos e $71,3 \%$ nos juizados autônomos). A Defensoria Pública realiza a acolhida de parcela significativa dos demais, em conjunto com os núcleos de prática jurídica e outros. (BRASIL, 2020a, p. 68)

25 Bacellar (2020, p. 217) recomenda enfaticamente essa triagem, salientando que não é apropriado simplesmente agendar uma audiência de mediação ou conciliação, sem avaliar antecipadamente as alternativas. O ideal é que, após uma análise prévia, haja o encaminhamento preciso para a porta que repute mais consentânea, optando-se, na hipótese de dúvida, pela conciliação. Nada impede, segundo o autor, que o conciliador reveja essa indicação preliminar, frente ao contato ulterior e mais próximo com o caso, redirecionando a análise para outro caminho que entenda mais adequado. 
caso identificada a sua propriedade. Quiçá, com o direcionamento a plataformas informatizadas de resolução, quando pertinente ${ }^{26}$.

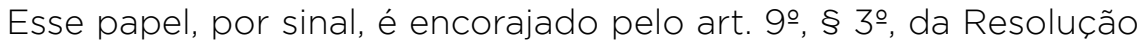
CNJ n. 125/2010, que determina aos tribunais a manutenção, nos Cejuscs, de pelo menos um servidor, com dedicação exclusiva e capacitação em métodos consensuais de solução de conflitos, para triagem e encaminhamento adequado de casos (BRASIL, 2010). Inclusive, com a unificação dos setores de atermação dos juizados especiais e dos centros, onde ainda subsista tal separação ${ }^{27}$.

Caso esse filtro antecipado não seja possível, o que ocorrerá amiúde com as ações propostas diretamente, por meio de advogados constituídos, convém que haja uma triagem das iniciais, ainda que posteriormente ao agendamento automático das audiências. Com a devida identificação dos autos, o profissional responsável pela audiência, seja o conciliador, juiz leigo ou togado, estará de antemão alerta à conveniência de abordar a mediação como alternativa, frente a um possivel desinteresse na conciliação imediata.

Unidades judiciárias com grande volume de ações em curso e de distribuição intensa podem não dispor de meios para esse crivo preliminar. Ressalta-se nesse passo, em termos de administração judiciária, que uma boa triagem é em regra vantajosa, porque há um investimento inicial de tempo e esforço que resulta em minimização de esforços futuros. Tratase de uma questão estratégica. Mas como essa não é uma realidade universalmente factível, sugere-se que haja esse foco, quando nada, no

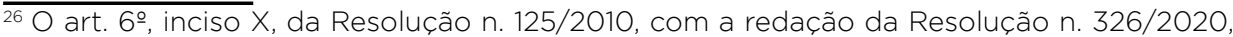
preconiza a criação de um Sistema de Mediação e Conciliação Digital ou a distância para atuação pré-processual de conflitos, sem prejuízo de sua utilização nas demandas em curso, mediante adesão dos tribunais.

27 A centralização das estruturas judiciárias está prevista no art. 2ㅜ, inciso I, da Resolução CNJ n. 125/2010. Não se trata ainda de uma realidade homogênea. "Nos juizados adjuntos, em $20,9 \%$ dos casos há uma central de conciliação que atende a varas e juizados; enquanto nos juizados autônomos, essa percentagem é de apenas 17,2\%; as equipes exclusivas da unidade judiciária estão presentes em $20 \%$ dos juizados adjuntos; já nos juizados autônomos esse percentual é o de maior convergência, com 43,4\%; magistrados e servidores também se ocupam dessa tarefa em 21,2\% e 15,3\% dos casos, respectivamente, nos juizados adjuntos; enquanto nos juizados autônomos, esse percentual é menor tanto para magistrados (11,7\%) quanto para servidores $(6,4 \%)$ - o que indica que as equipes exclusivas de conciliação estão absorvendo mais essa atividade nesses juizados. Soma-se a isso o fato de que 10,9\% dos informantes indicaram a existência de uma central de conciliação que atende somente aos juizados autônomos; esse percentual nos juizados adjuntos cai para 7,6\%". (BRASIL, 2020a, p. 70)
} 
curso da audiência em si, não se resumindo ao mero questionamento sobre haver ou não acordo.

Muitas vezes, nuances do litígio, que podem sugerir a conveniência da mediação, só virão à tona por ocasião dos diálogos preliminares à conciliação ou, quiçá, ao tempo da instrução da causa ${ }^{28}$. Por conseguinte, é lícito ao magistrado, no ato da colheita da prova ou no momento de deliberar sobre o mérito, instar novamente as partes a se manifestarem sobre o interesse na autocomposição, feitos os devidos esclarecimentos na audiência em andamento ou por outro meio menos formal, caso necessite converter em diligência o julgamento nos autos conclusos.

A possibilidade de designação de sessão de conciliação/prémediação pelo juiz, mesmo no curso do procedimento do juizado especial cível, extrai-se do art. 27 da Lei de Mediação. A norma, em primeira leitura, tem caráter cogente para o magistrado e, harmonizada com os ditames da Lei n. 9.099/1995, permite que o rito seja assim encaminhado, caso se identifique, em qualquer fase do processo, a conveniência e adequação dessa modalidade. Ademais, o art. 139, V, do CPC, faculta ao juiz promover a qualquer tempo a autocomposição, preferencialmente com o auxílio de conciliadores e mediadores. Não se trata, como abordado anteriormente, de imposição às partes de que se submetam ao procedimento, mas apenas à audiência (sessão), em que serão prestados os esclarecimentos e feitas as exortações necessárias.

O percurso pode ser bidirecional. Não há empecilho a que, iniciada a mediação no Cejusc, sem êxito na composição de todos os aspectos do conflito, apenas os remanescentes sejam direcionados à adjudicação.

O art. 3ำ, § 1, da Lei de Mediação, prevê que o procedimento poderá abarcar todo o conflito, ou apenas parte dele. E nada obsta que questões estranhas ao objeto do processo sejam ventiladas no curso da mediação e venham a ser incorporadas a eventual ajuste celebrado.

A bifurcação do rito, nesse caso, permite até que terceiros alheios à lide formal, mas partícipes do conflito material, sejam chamados a

\footnotetext{
${ }^{28}$ Nessa tônica, Bacellar (2020, p. 211) sustenta que: "No sistema norte-americano, a maioria dos acordos ocorre após a realização de algumas investigações dos fatos, um dos benefícios do modelo (Discovery)". No processo civil brasileiro, de acordo com o autor, o art. 381, inciso III, do CPC, está imbuído desse mesmo desiderato, facultando a produção autônoma e antecipada de provas, como mecanismo de prevenção ao ajuizamento de demandas.
} 
intervir na mediação, possibilitando a resolução do conflito de modo mais abrangente ${ }^{29}$. O art. 57, caput, da Lei n. 9.099/199530 favorece essa interpretação, em conjugação com o art. 515, § 2ำ do CPC ${ }^{31}$.

Em regra, as partes devem participar da mediação ou conciliação judicial acompanhadas de advogado ou defensor público. No entanto, há ressalva quanto ao rito dos juizados, em face da capacidade postulatória conferida à parte, até o teto de 20 salários mínimos, conforme art. 26, caput, da Lei de Mediação (Lei n. 13.140/2015), e art. 9º, caput, da Lei n. 9.099/1995.

De toda sorte, um dos objetivos da Política Judiciária Nacional de Tratamento Adequado dos Conflitos de Interesses, inscrito no art. 20 da Resolução CNJ n. 125/2010, é precisamente a disseminação da cultura de pacificação social, o que pressupõe educação dos cidadãos e qualificação dos profissionais, com ampla circulação das informações pertinentes.

A política nacional albergada pela Resolução CNJ n. 125/2010, abrange a interlocução com os órgãos essenciais à administração da justiça, estimulando sua participação nos Cejuscs e valorizando a atuação preventiva dos litígios (arts. 5 e 6으, inciso VI). Cuida-se de iniciativa intrínseca à formação de uma rede de incentivo à autocomposição de conflitos e à pacificação social, por meio da conciliação e da mediação. Tal desiderato de forma alguma pode esgotar-se no seio do Poder Judiciário, sendo imprescindível a cooperação das instituições públicas e privadas, com realce para a advocacia.

Ainda sobre a forma extrínseca do ato e a acessibilidade, proporcionase a sua realização a distância, quando conveniente. A mediação virtual está assentada no art. 46, caput, da Lei de Mediação, e exige concordância dos envolvidos. Ao passo que a sessão de conciliação virtual, no âmbito

\footnotetext{
${ }^{29}$ Exemplo extraído da prática forense encontramos em uma ação possessória. No curso da audiência de conciliação, verificou-se que as partes eram sogra e nora e que a presença da ré no imóvel, base do conflito, devia-se em realidade à disputa patrimonial com seu ex-companheiro, filho da autora, atinente à meação. As partes foram esclarecidas sobre o cabimento da mediação e consentiram na remessa ao Cejusc. Ali, houve êxito na composição do litígio, com a participação do companheiro, abarcando a totalidade dos interesses envolvidos. Solucionou-se o processo do juizado especial e preveniu-se a instauração de nova demanda em caráter contencioso, na vara de família.

30 "Art. 57. O acordo extrajudicial, de qualquer natureza ou valor, poderá ser homologado, no juízo competente, independentemente de termo, valendo a sentença como título executivo judicial." (BRASIL,1995)

31 "Art. 515. [...] \& 2ำ A autocomposição judicial pode envolver sujeito estranho ao processo e versar sobre relação jurídica que não tenha sido deduzida em juízo." (Brasil, 2015a)
} 
da Lei n. 9.099/1995, dispensa essa aquiescência, como deflui do art. 22, $\S 2^{\circ}$ e art. 23 (com a redação da Lei n. 13.994/2020). Neste último caso, porém, é curial que seja resguardada a possibilidade de comparecimento e participação em sala adequada, na sede do juízo ou outro lugar apropriado, haja vista a eventual hipossuficiência tecnológica da parte. Sob pena de, ignorando o fenômeno da exclusão digital, perpetrar-se um atentado contra a isonomia e o pleno acesso à justiça.

Às partes também é lícito firmar um negócio jurídico processual, com a suspensão do processo instaurado, para que as sessões de mediação propriamente dita prossigam a posteriori, máxime com o auxílio dos Cejuscs (art. 16, caput, da Lei de Mediação).

Convém, tanto quanto possível, que o profissional responsável pela pré-mediação ou pela condução da audiência não seja o mesmo que venha a desenvolver as sessões posteriores, a fim de que se mantenha neutro em relação à lide.

A celeridade, visualizada unicamente a partir do tempo de resposta do Judiciário, pode parecer comprometida à primeira vista. No entanto, a oportunidade para emancipar ${ }^{32}$ as partes e prevenir litígios futuros ${ }^{33}$ por si mesma justifica a abordagem, que visa ganhos de longo prazo. "Objetivos como melhorar o relacionamento ou minimizar custos do processo de resolução da controvérsia podem ser facilmente atingidos por meio da mediação, e muito dificilmente por meio da adjudicação". (FALECK, 2018, p. 120)

Isso porque não é raro que as pretensões e posições externadas no processo ocultem interesses ${ }^{34}$ e conflitos laterais que podem se

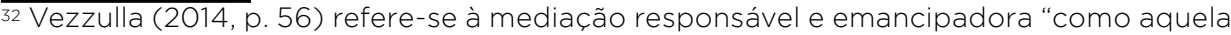
onde o mediador se responsabiliza cuidadosamente, com os mediados, de que o acordo planejado atenda realmente às necessidades de todos, cuidando especialmente da repercussão da sua implementação e examinando as consequências individuais e sociais de seu cumprimento ou não."

33 "Qualquer solução que não atenda às necessidades e os direitos de ambos os conflitantes não será cumprida senão pela ameaça ou pelo uso de violência e deixará sempre em aberto o rebrote do mesmo problema na busca de revanche de quem ficou insatisfeito e magoado por não ter sido ouvido, atendido e compreendido seu ponto de vista, seus direitos." (VEZZULLA, 2013, p. 75)

${ }^{34}$ Conforme Tartuce e Faleck (2014, p. 12): "Os interesses são as necessidades, os desejos e os medos ligados à preocupação ou à vontade de alguém; permeiam a 'posição', que compreende os itens tangíveis que alguém diz querer".
} 
perpetuar, mal resolvidos, mesmo diante de um julgamento de mérito ${ }^{35}$. Para Bacellar (2016, p. 109), "com a mediação, é possível o conhecimento global da causa e a resolução integral do conflito, preservando-se o relacionamento anterior entre os litigantes". O juiz, então, deve estar preparado a reconhecer essas circunstâncias e, quando preciso, recomendar a mediação ${ }^{36}$.

Pesquisas envidadas alhures revelam que a percepção da justiça do processo e do resultado obtido são positivamente influenciadas pelo grau de envolvimento das partes (BACELLAR, 2016, p. 135). De igual modo, sustenta-se que o número de execuções de ajustes firmados de forma efetivamente dialogada seria substancialmente menor, em comparação com os títulos adjudicados. As partes teriam maior propensão a cumprir com um acordo que fizeram por elas mesmas do que com um resultado imposto por outrem. (FALECK, 2018, p. 119)

A par da efetiva harmonização dos interesses, suficiente para justificar essa abordagem, é preciso frisar que a redução, ainda que módica, no volume de execuções não é uma meta de somenos importância.

De acordo com o relatório Justiça em Números, os processos de execução respondem por mais da metade do acervo de 77 milhões de processos $(55,8 \%)$ em trâmite e constituem a etapa de maior morosidade. Segundo as séries históricas, ingressam quase duas vezes mais casos de conhecimento do que de execução, no entanto, o estoque é maior na fase executória, em proporção aos casos novos (BRASIL, 2020b, p. 150). Do percentual de sentenças homologatórias de acordos, em 2019, que foi de somente 12,5\%, 6,1\% ocorreram na execução, e 19,6\% em média na fase de conhecimento. (BRASIL, 202Ob, p. 171)

\footnotetext{
35 "Voltando à hipótese de relação continuada [...] cabe destacar que a imposição de uma decisão, por certo, irá dizer o direito pertinente, mas a resolução do conflito, mesmo que imediatamente, não ocorrerá necessariamente, pois as partes podem simplesmente não concordar com a solução internalizada na relação pelo Estado. É por este motivo que o juiz deve se preocupar também com os efeitos que sua decisão cria (Ada Pellegrini Grinover, 2013). Nesta esteira, revela-se que a adjudicação imporá, por muitas vezes, a existência de uma zona de tensão na relação jurídica, o que é absolutamente nocivo à sua continuidade." (SILVA, 2018. p. 455)

36 "Não é preciso que o magistrado domine as técnicas de mediação, mas, sim, que ele entenda a aplicabilidade do processo e em como as partes podem ser auxiliadas até o acordo. O diagnóstico dos casos é um ponto essencial em que o magistrado pode contribuir com a institucionalização da mediação. Muitas vezes esse encaminhamento vai além de um ato formal e inclui um trabalho difícil de convencimento que não pode coagir, mas pode persuadir as partes ao intento do diálogo." (ANDRADE, 2018, p. 219)
} 
Então, o tempo devotado a essa triagem e esclarecimento, com vistas aos meios autocompositivos mais apropriados, pode reverter em ganhos significativos a posteriori, com a prevenção de novos conflitos e redução do número de cumprimentos involuntários de sentenças.

Acerca dessa visão prospectiva da mediação e sobre o seu escopo diferenciado da conciliação stricto sensu, rememora-se a lição de Vezzulla (2014, p. 58-59):

[...] é importante ressaltar que a mediação não deve ser confundida com a conciliação nem com o objetivo de conciliar que remete mais a procedimentos onde o que se deseja é poder chegar a um acordo negociado por meio de concessões mútuas.

Na mediação, seus objetivos e meios são outros. Procuramos conseguir cooperativamente a programação do futuro da relação entre os participantes que atenda todas as necessidades em jogo com a consciência da responsabilidade mútua.

Perceba-se que não se pretende resolver um problema do passado, mas sim o de trabalhar desde o presente, contando com a experiência passada, o relacionamento, o modo de estarmos e sermos juntos no futuro nas questões que nos unem.

Não se cogita aqui da pressão exercida, conscientemente ou não, sobre a vontade das partes para extinguir processos, mas das composições genuinamente espontâneas ou auxiliadas por terceiros hábeis e capacitados, com pleno respeito à autonomia dos envolvidos ${ }^{37}$. "Mais do que conduzir à extinção de processos judiciais, por acordo, é significativo que se tenha a percepção de que certos casos recomendam aprofundar o conhecimento da causa além daquilo que é apresentado". (BACELLAR, 2016, p. 109)

Veja-se que a realização de um filtro em momento oportuno e o respeito à autonomia das partes significará, ao cabo, que apenas um

\footnotetext{
37 O código de ética de conciliadores e mediadores judiciais, anexo à Resolução CNJ n. 125/2010, é categórico ao fixar a "ausência de obrigação de resultado", consignando o "dever de não forçar um acordo e de não tomar decisões pelos envolvidos, podendo, quando muito, no caso da conciliação, criar opções, que podem ou não ser acolhidas por eles". (BRASIL, 2010)
} 
percentual do volume de demandas efetivamente será desviado de seu curso usual para a mediação. No entanto, o foco está na qualidade do serviço oferecido e na efetividade da resolução do conflito ${ }^{38}$, não necessariamente na quantificação estatística ${ }^{39}$, conquanto sejam ambas igualmente preocupações da gestão superior do Poder Judiciário, legítimas e subsumidas em sua missão institucional.

\section{CONCLUSÃO}

Os juizados especiais cíveis estaduais nasceram vocacionados à autocomposição. Com suas portas abertas aos cidadãos, convidam à busca da tutela jurisdicional, mas sem descurarem dos métodos consensuais de pacificação dos conflitos. Antes, buscam difundi-los e estimulá-los, como parte de sua missão constitucional de proporcionar uma justiça simples, célere e eficaz.

Estabelecido o seu papel pioneiro, o que é demonstrado por uma expansão colossal da procura de seus serviços e pelos elevados indices de resolutividade, cabe ao microssistema estar aberto à evolução, abraçando o que de melhor se implantou no ordenamento jurídico nacional, desde o seu advento.

Harmonizados os princípios que o estruturam, os juizados especiais podem se abeberar, pelo método do diálogo das fontes, dos regramentos instituídos em torno dos métodos consensuais de resolução de conflitos, mormente os insculpidos na Lei de Mediação, no Código de Processo Civil e na Resolução CNJ n. 125/2010.

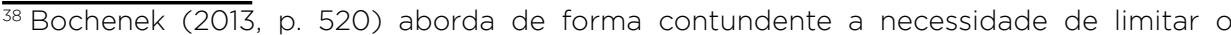
acesso aos tribunais, para ampliar o acesso aos direitos e à justiça, e vaticina: "O que fazer para limitar e ampliar? Fomentar uma nova concepção de acesso aos direitos e à justiça voltada para a integração entre os órgãos de poder, com as entidades públicas, privadas e os movimentos sociais, com o objetivo de diminuir o número de demandas que não necessitariam ingressar nos tribunais, pois são melhores solucionados na via administrativa ou por outras formas de resolução de conflito".

39 "Esses mecanismos ditos 'alternativos' de resolução de controvérsias devem ser estudados e organizados não como solução para a crise de morosidade da Justiça, como uma forma de reduzir a quantidade de processos acumulados no Judiciário, e sim como métodos para dar tratamento mais adequado aos conflitos de interesses que ocorrem na sociedade. A redução dos processos será uma resultante necessária do êxito de sua adoção, mas não seu escopo primordial." (WATANABE, 2018, p. 839)
} 
Cabe aos operadores do direito e aos colaboradores da justiça, que atuam nesse âmbito, estarem informados e atentos às peculiaridades dos conflitos, para diagnosticarem as situações em que, pelos contornos do litígio, outros métodos alternativos à adjudicação e à conciliação se revelem mais apropriados, com realce para a mediação.

Uma vez que a informação adequada e a voluntariedade estão na raiz da tomada de decisões conscientes pelos partícipes do conflito, vislumbra-se a audiência de conciliação, compulsória no rito dos juizados, como oportunidade ótima para que sejam prestados os indispensáveis esclarecimentos, utilizando-se esse espaço para a pré-mediação. Apresentadas as características, os princípios e métodos da mediação, defere-se ao crivo das partes optarem pelo método. A ausência de expressa previsão legal não elide essa abordagem, antes a favorece, dada a informalidade do rito, que permite seja o mesmo plasmado às peculiaridades do caso.

A oferta de um leque expandido de oportunidades de métodos cooperativos aos litigantes, além de proporcionar o incremento do índice de acordos, de reduzir a insatisfação com o resultado obtido e de minimizar o tempo e esforço dedicados à execução dos títulos judiciais, tem por consectário esperado, no que concerne à mediação, a reabertura dos canais do diálogo e o fortalecimento das relações preexistentes entre as partes, emancipando-as e, idealmente, mitigando a probabilidade de conflitos futuros.

O acesso pleno à justiça convola-se em instrumento de educação dos cidadãos sobre as habilidades e capacidades latentes para dirimirem seus conflitos, no espaço de autonomia e interlocução que ocupam no ambiente social. 


\section{REFERÊNCIAS}

ANDRADE, Juliana Loss de. Magistratura \& mediação. In: Zaneti Jr., Hermes; Cabral, Trícia Navarro Xavier (coord.). Justiça Multiportas: mediação, conciliação, arbitragem e outros meios adequados de solução de conflitos. 2. ed. Salvador: Juspodivm, 2018. cap. 9, p. 215223.

BACELLAR, Roberto Portugal. Mediação e arbitragem. 2. ed. São Paulo: Saraiva, 2016.

BACELLAR, Roberto Portugal. As lições da ADR para aumentar os índices de acordo e a ressurreição da conciliação. In: Lagrasta, Valeria Ferioli; Ávila, Henrique de Almeida (org.). Política judiciária nacional de tratamento adequado dos conflitos de interesses: 10 anos da Resolução CNJ n. 125/2010. São Paulo: IPAM, 2020. p. 205-223.

BOCHENEK, Antônio César. A interação entre tribunais e democracia por meio do acesso aos direitos e à justiça: análise de experiências dos juizados especiais federais cíveis brasileiros. Brasília: CJF, 2013.

BRASIL. Conselho Nacional de Justiça. Resolução n. 125, de 29 de novembro de 2010. Dispõe sobre a Política judiciária nacional de tratamento adequado dos conflitos de interesses no âmbito do Poder judiciário e dá outras providências. Diário de Justiça Eletrônico/CNJ: Brasília, DF, n. 219, p. 2-14, 1 dez. 2010. Disponível em: https://atos.cnj.jus. br/atos/detalhar/156. Acesso em: 10 jan. 2021.

BRASIL. Conselho Nacional de Justiça. Diagnósticos dos juizados especiais. Brasília, 2020a. Disponível em: https://www.cnj.jus.br/wpcontent/uploads/2020/08/WEB_LIVRO_JUIZADOS_ESPECIAIS.pdf. Acesso em: 10 jan. 2021.

BRASIL. Conselho Nacional de Justiça. Justiça em Números 2020: ano-base 2019. Brasília, 2020b. Disponível em: https://www.cnj.jus.br/ pesquisas-judiciarias/justica-em-numeros/. Acesso em: 10 jan. 2021.

BRASIL. [Constituição (1988)]. Constituição da República Federativa do Brasil de 1988. Brasília, DF: Presidência da República, [2021]. Disponível em: http://www.planalto.gov.br/ccivil_03/constituicao/ constituicao.htm. Acesso em: 6 jan. 2021. 
BRASIL. Lei n. 9.099, de 26 de setembro de 1995. Dispõe sobre os Juizados Especiais Cíveis e Criminais e dá outras providências. Diário Oficial da União: seção 1, Brasília, DF, ano 133, n. 185, p. 15034-15037, 27 de setembro de 1995. Disponível em: http://www.planalto.gov.br/ ccivil_03/leis/I9099.htm. Acesso em: 6 jan. 2021.

BRASIL. Lei n. 13.105, de 16 de março de 2015. Código de processo civil. Diário Oficial da União: seção 1, Brasília, DF, ano 152, n. 51, p. 1-51, 17 mar. 2015a. Disponível em: http://www.planalto.gov.br/ccivil_03/_ato20152018/2015/lei/l13105.htm. Acesso em: 6 jan. 2021.

BRASIL. Lei n. 13.140, de 26 de junho de 2015. Dispõe sobre a mediação entre particulares como meio de solução de controvérsias e sobre a autocomposição de conflitos no âmbito da administração pública.

Diário Oficial da União: seção 1, Brasília, DF, ano 152, n. 121, p. 4-6, 29 jun. 2015b. Disponível em: http://www.planalto.gov.br/ccivil_03/_ ato2015-2018/2015/lei/113140.htm. Acesso em: 11 jan. 2021.

CÂMARA, Alexandre Freitas. Juizados especiais cíveis estaduais e federais: uma abordagem crítica. 4. ed. Rio de Janeiro: Lumen Juris, 2008.

CURY, Cesar Felipe. Mediação. In: Zaneti Jr., Hermes; Cabral, Trícia Navarro Xavier (coord.). Justiça Multiportas: mediação, conciliação, arbitragem e outros meios adequados de solução de conflitos. 2. ed. Salvador: Juspodivm, 2018. cap. 19, p. 495-520.

FALECK, Diego. Manual de design de sistemas de disputas: criação de estratégias e processos eficazes para tratar conflitos. Rio de Janeiro: Lumen Juris, 2018.

FIGUEIRA JÚNIOR, Joel Dias; Tourinho Neto, Fernando da Costa. Juizados especiais estaduais cíveis e criminais: comentários à Lei n. 9.099/1995. 8. ed. São Paulo: Saraiva, 2017.

GALVÃO FILHO, Maurício Vasconcelos. Audiência(s) e sessão(ões) de mediação na Lei de mediação (Lei n. 13.140/2015) e no novo Código de processo civil brasileiro (Lei n. 13.105/2015). In: Zaneti Jr., Hermes; Cabral, Trícia Navarro Xavier (coord.). Justiça Multiportas: mediação, conciliação, arbitragem e outros meios adequados de solução de conflitos. 2. ed. Salvador: Juspodivm, 2018. cap. 20, p. 521-544. 
LUCHIARI, Valeria Ferioli Lagrasta. Desafios do artigo 334 do CPC/2015. Revista de Processo, São Paulo, v. 303, p. 503-516, maio 2020. Disponível em: www.revistadostribunais.com.br. Acesso em: 12 jan. 2021.

MENDES, Aluisio Gonçalves de Castro; Hartmann, Guilherme Kronemberg. A audiência de conciliação ou de mediação no novo Código de Processo Civil. In: Zaneti Jr., Hermes; Cabral, Trícia Navarro Xavier (coord.). Justiça Multiportas: mediação, conciliação, arbitragem e outros meios adequados de solução de conflitos. 2. ed. Salvador: Juspodivm, 2018. cap. 5, p. 109-128.

NICÁClO, Camila Silva. Desafios e impasses aos meios consensuais de tratamento de conflitos. In: Gunther, Luiz Eduardo; Pimpão, Rosemarie Diedrichs (coord.). Conciliação, um caminho para a paz social. Curitiba: Juruá, 2012. v. 1, cap. 3, p. 25-46.

PEIXOTO, Ravi. Os "princípios" da mediação e da conciliação: uma análise da Res. 125/2010 do CNJ, do CPC/2015 e da Lei 13.140/2015. In: Zaneti Jr., Hermes; Cabral, Trícia Navarro Xavier (coord.). Justiça Multiportas: mediação, conciliação, arbitragem e outros meios adequados de solução de conflitos. 2. ed. Salvador: Juspodivm, 2018. cap. 4, p. 91-107.

SILVA, Irapuã Santana do Nascimento da. Existe possibilidade de acordo no novo CPC?. In: Zaneti Jr., Hermes; Cabral, Trícia Navarro Xavier (coord.). Justiça Multiportas: mediação, conciliação, arbitragem e outros meios adequados de solução de conflitos. 2. ed. Salvador: Juspodivum, 2018. cap. 17, p. 451-470.

TARTUCE, Fernanda; Faleck, Diego. Introdução histórica e modelos de mediação. [S. I.], 2014. Disponível em: http://www.fernandatartuce.com. $\mathrm{br} / \mathrm{wp}$-content/uploads/2016/06/Introducao-historica-e-modelos-demediacao-Faleck-e-Tartuce.pdf. Acesso em: 8 jan. 2021.

VEZZULLA, Juan Carlos. A mediação: para uma análise da abordagem dos conflitos à luz dos direitos humanos, o acesso à justiça e o respeito à dignidade humana. In: Silva, Luciana Aboim Machado Gonçalves da (org.). Mediação de conflitos. São Paulo: Atlas, 2013, p. 63-93.

VEZZULLA, Juan Carlos. Mediação responsável e emancipadora: reflexões sobre a atuação dos advogados. Revista do Advogado AASP, São Paulo, v. 34, n. 123, p. 56-61, ago. 2014. 
WATANABE, Kazuo. Acesso à justiça e solução pacífica dos conflitos de interesses. In: Zaneti Jr., Hermes; Cabral, Trícia Navarro Xavier (coord.). Justiça Multiportas: mediação, conciliação, arbitragem e outros meios adequados de solução de conflitos. 2. ed. Salvador: Juspodivm, 2018. cap. 37, p. 833-841.

WATANABE, Kazuo. Acesso à ordem jurídica justa: conceito atualizado de acesso à justiça, processos coletivos e outros estudos. Belo Horizonte: Del Rey, 2019.

WATANABE, Kazuo. Atualização do conceito de acesso à justiça. In: Ávila, Henrique de Almeida; Lagrasta, Valeria Ferioli. Política judiciária nacional de tratamento adequado dos conflitos de interesses: 10 anos da Resolução CNJ n. 125/2010. São Paulo: IPAM, 2020. cap. 9, p. 133-137. 